\title{
REIFICATION AND THE CONSCIOUSNESS OF THE PATIENT
}

\author{
Michael T. TAUSSIG \\ Department of Anthropology, The University of Michigan, \\ Ann Arbor, MI 48109, U.S.A.
}

\begin{abstract}
The signs and symptoms of disease do something more than signify the functioning of our bodies; they also signify critically sensitive and contradictory components of our culture and social relations. Yet, in our standard medical practices this social "language" emanating from our bodies is manipulated by concealing it within the realm of biological signs. I try to show this by means of a patient's interpretation of the meaning of her illness. This case study illustrates that in denying the human relations embodied in signs, symptoms, and therapy, we mystify those relations and also reproduce a political ideology in the guise of a science of physical things. This I call reification, following Karl Marx's analysis of the commodity and Georg Lukács' application of this analysis to the interpretation of capitalist culture and its mode of objectifying social relations. I argue that in sustaining reification, our medical practice invigorates cultural axioms as well as modulating the contradictions intrinsic to our culture and views of objectivity. In this way disease is recruited into serving the ideological needs of the social order, to the detriment of healing and our understanding of the social causcs of misfortune.
\end{abstract}

\section{THE MARXIST PROBLEM: REIFICATION}

By means of a cultural analysis of an illness and its treatment in the USA in 1978 , I wish to direct attention to the importance of two problems raised by Marxism and hy anthropology concerning the moral and social significance of biological and physical "things". I am going to argue that things such as the signs and symptoms of disease, as much as the technology of healing, are not "things-in-themselves", are not only biological and physical, but are also signs of social relations disguised as natural things, concealing their roots in human reciprocity.

The problem raised by Marxism comes from the famous essay of Georg Lukács published in 1922 entitled "Reification and the Consciouness of the Proletariat", an essay which had explosive impact on the European Communist movement, in good part due to its critique of "historical materialism" as developed by Engels, Lenin, and the theoreticians of the German Social Democrat Party. In essence, Lukács charged that the concept of objectivity held by capitalist culture was an illusion fostered by capitalist relations of production and that this concept of objectivity had been thoughtlessly assimilated by Marxist critics who were, therefore, upholding basic categories of the social form they thought they were impugning. Lukács attempted to construct a critical sociology of bourgeois knowledge which assailed the very theory of knowledge or epistemology which he felt was basic to capitalist culture. The Kantian and neo-Kantian antinomies between "fact" and "value", as much as the empiricist copy-book theory of knowledge sharply dividing "objectivity" from "subjectivity", were, in Lukács opinion, tools of thought which reproduced capitalist ideology (even if they were deployed within a so-called "historical materialist" framework of analysis). The roots of the thought-form which took the capitalist categories of reality for granted were to be found, he argued, in what he called the "commodity-structure", and a chief aim of his essay was to draw attention to the central importance of the analysis of commodities in Marx' portrayal and critique of capitalism. There was no problem in this stage of history, claimed Lukács, that did not lead back to the question of the commodity structure, the central, structural problem of capitalist society in all its aspects. Intrinsic to this problem lay the phenomenon of reification-the thingification of the world, persons, and experience, as all of these are organized and reconstituted by market exchange and commodity production. The basis of commodity-structure, wrote Lukács, "is that a relation between people takes on the character of a thing and thus acquires a 'phantom objectivity', an autonomy that seems so strictly rational and all-embracing as to conceal every trace of its fundamental nature: the relation between people" [1].

It is with the phantom-objectivity of disease and its treatment in our society that I am concerned, because by denying the human relations embodied in symptoms, signs, and therapy, we not only mystify them but we also reproduce a political ideology in the guise of a science of (apparently) "real things"-biological and physical thinghood. In this way our objectivity as presented in medicine represents basic cultural axioms and modulates the contradictions inherent to our culture and view of objectivity. Rather than expound further, I now wish to exemplify these all too abstract orienting premises by means of a concrete ethnographic analysis of a sickness. But before doing so, I have to draw attention to a problem raised by anthropology, namely by Evans-Pritchard's classic analysis of Azande witchcraft published in 1937 [2].

\section{THE ANTHROPOLOGICAL PROBLEM: THE BIOLOGICAL BODY AND THE SOCIAL BODY}

It is surely a truism that the sense of self and of the body change over time and vary between different 
cultures. In modern capitalist culture the body acquires a dualistic phenomenology as both a thing and my being, body and "soul". Witness Sartre's chapters on the body in Being and Nothingness [3].

Of course the physicians who have taken care of me, the surgeons who have operated on me, have been able to have direct experience with the body which I myself do not know. I do not disagree with them. I do not claim that I lack a brain, a heart, or a stomach. But it is most important to choose the order of our bits of knowledge. So far as the physicians have had any experience with my body, it was with my body in the midst of the world and as it is for others. My body as it is for me does not appear to me in the midst of the world. Of course during a radioscopy I was able to see the picture of my vertebrae on a screen, but I was outside in the midst of the world. I was apprehending a wholly constituted object as a this amongst other thises, and it was only a reasoning process that I referred it back to being mine; it was much more my property than my being.

As it oscillates between being my property and my. being, especially when diseased, my body asks me questions which the physician never ask or answer: "Why me?", "Why now?" As Evans-Pritchard observed, these are the questions foremost in the Azande attribution of serious sickness or misfortune to witcheraft or sorcery-i.e. to the malevolent disposition of critically relevant social relationships. Science, as we understand it in our day and age, cannot explain the human significance of physical effects. To cite the common phraseology, science, like medical science, can explain the "how" but not the "why" of disease; it can point to chains of physical cause and effect, but as to why 1 am struck down now rather than at some other time, or as to why it is me rather than someone else, medical science can only respond with some variety of probability theory which is unsatisfactory to the mind searching for certainty and for significance. In Azande practice, the issues of "how" and "why" are folded into one another; aetiology is simultaneously physical, social, and moral. The cause of my physically obvious distress is to be located in my nexus of social relations involving someone else's unjustly called for malevolence. This property of my social nexus expresses itself in physical symptoms and signs. My disease is a social relation, and therapy has to address that synthesis of moral, social, and physical presentation.

There are two problems raised by this account. First, do patients in our society also ask themselves the questions that Azande do, despite the disenchantment of our age and its incredulity regarding witchcraft and sorcery? Second, have we not falsified Azande epistemology, following Evans-Pritchard, in distinguishing the "how" from the "why", "lact" from "value", and immediate from ultimate causes? Unless we firmly grasp at the outset that these are not the salient native distinctions but that they are ours which we necessarily deploy in order to make some sense out of a foreign epistemology, we will fail to appreciate what is at issue. The salient distinction to note is that in Azande epistemology there is a vastly different conception of facts and things. Facts are not separated from values, physical manifestations are not torn from their social contexts, and it requires therefore no great effort of mind to read social relations into material events. It is a specifically modern problem wherein things like my bodily organs are at one instant mere things, and at another instant question me insistently with all too human a voice regarding the social significance of their dis-ease.

Paul Radin in his discussion of the concept of the self in "primitive" societies makes the same point. He suggests that the objective form of the ego in such societies is generally only intelligible in terms of the external world and other egos. Instead of the ego as a thing-in-itself, it is seen as indissolubly integrated with other persons and with nature. "A purely mechanistic conception of life," he concludes, "is impossible. The parts of the body, the physiological functions of the organs, like the material objects taken by objects in nature, are mere symbols, simulacra, for the essential psychical-spiritual entity that lies behind them" [4].

As it oscillates between being a thing and my being, as it undergoes and yet disengages itself from reification, my body responds with a language that is as commonplace as it is startling. For the body is not only this organic mosaic of biological entities. It is also a cornucopia of highly charged symbols-fluids. scents, tissues, different surfaces, movements, feelings. cycles of changes constituting birth, growing old, sleeping and waking. Above all, it is with disease with its terrifying phantoms of despair and hope that my body becomes ripe as little else for encoding that which society holds to be real-only to impugn that reality. And if the body becomes this important repository for generating social meaning, then it is in therapy that we find the finely gauged tuning whereby the ratification of socially engendered categories and the fabulation of reality reaches its acme.

In any society, the relationship between doctor and patient is more than a technical one. It is very much a social interaction which can reinforce the culture's basic premises in a most powerful manner. The sick person is a dependent and anxious person, malleable in the hands of the doctor and the health system, and open to their manipulation and moralism. The sick person is one who is plunged into a vortex of the most fundamental questions concerning life and death. The everyday routine of more or less uncritical acceptance of the meaning of life is sharply interrupted by serious illness which has its own pointed way of turning all of us into metaphysicians and philosophers, (not to mention critics of a society which leaves its sick and their families to fend for themselves). This gives the doctor a powerful point of entry into the patient's psyche, and also amounts to a destructuration of the patient's conventional understandings and social personality. It is the function of the relationship between the doctor and the patient to restructure those understandings and that personality; to bring them back into the fold of society and plant them firmly within the epistemological and ontological groundwork from which the society's basic ideological premises arise. In modern clinical practice and medical culture, this function is camouflaged. The issue of control and manipulation is concealed by the aura of benevolence. The social character of the medical encounter is not immediately obvious in the way that it is in the communal healing rites of "primitive" societies. With us, consultation and healing occurs in privatized and individualistic 
settings, and the moral and metaphysical components of disease and healing are concealed by the use of the natural science model.

As Susan Sontag has recently emphasized [5], while the symptoms and signs of disease usually have a decidely and all too material quality, they are something else besides. We might say that they are social as well as physical and biological facts. We glimpse this if we reflect but for a moment on the vastly different meanings conveyed by signs and symptoms at different points in history and in different cultures. Fatness, thinness, blood in one's urine, let alone blood per se, headache, nightmares, lassitude, coughing, blurred vision, dizziness, and so forth, acquire vastly different meanings and significance at different times in history, in different classes of society, and so on. Two points are raised here. The manifestations of disease are like symbols, and the diagnostician sees them and interprets them with an eye trained by the social determinants of perception. Yet this is denied by an ideology or epistemology which regards its creations as really lying "out-there"-solid, substantial thingsin-themselvves. Our minds like cameras or carbon paper do nothing more than faithfully register the facts of life. This illusion is ubiquitous in our culture, is what Lukács means by reification stemming from the commodity-structure, and medical practice is a singularly important way of maintaining the denial as to the social facticity of facts. Things thereby take on a life of their own, sundered from the social nexus that really gives them life, and remain locked in their own self-constitution.

Today in various nooks and crannies called consultation rooms, diagnosticians listen for the same elements and when they find them they do not say. I can put these things together and call them hysteria if I like (much as a little boy can sort his marbles now by size, now by colour, now by age); rather, the diagnostician, when he has completed his sort says: This patient is a hysteric! Here, then, is the creator denying authorship of his creation. Why? Because in turn he receives a greater prize; the reassurance that out there is a stable world; it is not all in his head [6].

What is revealed to us here is the denial of authorship, the denial of relationship, and the denial of the reciprocity of process to the point where the manifold armory of assumptions, leaps of faith and a priori categories are ratified as real and natural. In another idiom, the arbitrariness of the sign is disconfirmed and no longer seen as arbitrary because it is affixed in the patient, therewith securing the semiotic of the disease langue. And if the diagnostician is thereby reassured as to the reality of the world as thinghood writ large, and by this dispenses with the discomfort of being at too close quarters with the reality of what is but the social construction of reality, it is not that it is 'all in his head" but that it is all in the relationship of physicians and patients which is at stake. The relationship is worked over and sundered. Reciprocity lies victim to the assault performed on it. Likewise, the patient and the concept of disease have been recruited in the service of building a reality whose stability, which cannot be denied so long as professional expertise bears down, is nevertheless prone to violent altercations as the pressure of denied authorship and reciprocity makes its presence felt. This presence of denial is itself masked by the illusion of reciprocity of a different sort; the niceties of style in the bedside manner and the culture of caring. Foucault directs our attention to this in his discussion of changes in psychiatry, in terms that apply to all of modern clinical science:

Madness no longer exists except as seen. The proximity instituted by the asylum, an intimacy neither chains nor bars would violate again, does not allow reciprocity: only the nearness of observation that watches, that spies, that comes closer in order to see better, but moves ever further away, since it accepts and acknowledges only the values of the Stranger. The science of mental disease ... would not be a dialogue... [7].

Because it does this, medical practice inevitably produces grotesque mystifications in which we all flounder, grasping ever more pitifully for security in a man-made world which we see not as social, not as human, not as historical, but as a world of a priori objects beholden only to their own force and laws, dutifully illuminated for us by professional experts such as doctors. There are many political messages subtly encouraged by all of this for those who become patients, and we all become patients at some time, and we are all patients in a metaphorical sense of the social "doctors" who minister our needs. Don't trust your senses. Don't trust the feeling of uncertainty and ambiguity inevitably occurring as the socially conditioned senses try to orchestrate the multitude of meanings given to otherwise mute things. Don't contemplate rebellion against the facts of life for these are not in some important manner partially man-made, but are irretrievably locked in the realm of physical matter. To the degree that matter can be manipulated. leave that to "science" and your doctor.

\section{THE PATIENT}

By way of illustration (rigorously preserving the anonymity of the people and organizations involved) I want to discuss the situation of a 49 years-old white working class woman with a history of multiple hospital admissions over the past 8 years with a diagnosis of polymyositis-inflammation of many muscles. According to medical authority, this is a fatal chronic disease consisting in the progressive deterioration of muscle. Classified as a rheumatoid disease of unknown cause, treatment consists largely in the administration of heavy doses of steroids at the times when the disease waxes in order to decelerate the inflammation. I met her in the wards of a prestigious teaching hospital in 1978, where we talked for some $4 \mathrm{hr}$ on five occasions. I introduced myself as a physician and anthropologist, interested in patients views of sickness.

She described her condition as disease of the muscles. They deteriorate, and it's terminal. It is a terrible tiredness, she says, which comes and goes in relation to stress. What worries her is being without control during the acute phases. As she puts. it, the switch to her body, between her mind and body, becomes switched off. The attic is cut off from the basement. When she gives examples, it is always in situations where she is working for others; washing the dishes for example. When asked what she thought 
might be the cause of her disease, it turned out that she constantly asked herself why she had it, never stopped asking herself "why?"; "Why me, Oh Lord, why me?"

Her search for explanation and meaning remains dissatisfied with what the medical profession offers. As we shall see, she demands a totalizing synthesis which she herself provides by reading contradictory cultural themes into her symptoms, signs, and progress. These contradictions are exhibited by her reactions to the obiter dicta of medical professionals, to the patterns of discipline enforced by the hospital, and to the conflicts systematically coursing through society in general. Moreover, her mode of understanding and explanation runs counter to the master paradigms in our culture which dichotomize mind from matter, morality from physical determinism, and "things" from the social context and human meaning in which they inhere. In being foreign to accepted cultural consciousness in these crucial ways, her attempts to provide a synthetic understanding of physical things cannot but be tensed and prone to instability.

Her first response was to say that the cause of her condition is "an unhappy reason". At the age of 15 and contrary to her mother's desire, she married a factory worker who soon became unable to support her and the five children born in the following 5 years due to his alcoholism. She had a tubal ligation followed shortly thereafter by a re-stagement, and then six more pregnancies all resulting in miscarriages. She took in washing, ironed, and gleaned garbage for bottles which she sold. There was rarely money sufficient for food and she was constantly exhausted and hungry. She would go without food in order to give it to the children who were frequently sick. In turn, she caught many of their sicknesses, because she was so weak and tired. Life was this endless round of poverty, exertion, exhaustion, and sickness. "Surely that could cause polymyositis," she says. "You can take a perfect piece of cloth and if you rub it on the scrub board long enough, you're going to wear holes in it. It's going to be in shreds. You can take a healthy person and take away the things that they need that are essential, and they become thin and sickly. So I mean... it all just comes together." She has never approached her doctors with this idea because "They would laugh at my ignorance. But it does seem right; that tiredness and work all the time. Take the children of India without enough food, dragging their swollen bellies around, tired and hungry. Surely they could have this disease too. Only because they haven't got hospitals, nobody knows it."

In making these connections, the patient elaborates on the connection she has in mind between polymyositis as muscle degeneration and her life-experience of oppression, of muscular exertion, and of bodily sacrifice. What seems especially significant here is that the causes she imputes as well as her understanding of the disease stand as iconic metaphors and metonyms of one another, all mapped into the disease as the arch-metaphor standing for that oppression. This could well form the highly charged imagery leading to a serious critique of basic social institutions. But, as we shall see, other aspects of the situation mitigate this potentiality.
She then went on to develop the idea that there also exists an hereditary or quasi-hereditary causal factor. In her opinion. one of her daughters is possibly afflicted with the disease, and two of that daughter's daughters also. She feels extremely close to this daughter, to the point where she maintains that there is a mystical attachment between them, of Extra-Sensory Perception, as she says. Even when they are far apart physically, each one knows what is happening to the other, especially at a time of crisis, when they come to each other's aid. She elaborates on the concept that the disease is present in this matriline, manifesting itself in four distinct stages correlated to the four ages of the four females involved. In passing, it is worth noting that the males in the family history come in for little mention with the exception of her first husband who is seen as a destructive and even evil figure. Her immediate social world is seen by her as centered on the history of four generations of women, beginning with her mother who raised the family in dire poverty. This characteristic matriline or reciprocating women in the networks of working class families is in this case vividly expressed by the mystical closeness she feels for her daughter, and by the mapping of these social relations into the disease as a metaphor of those relations.

The fact that the youngest granddaughter involved was seriously ill when a few months of age, and that the doctors found an "orgasm" in her blood, suggests to the patient the possibility that a foreign-agent or bacterial aetiology plays a part too; the foreign-agent disappearing into the body to slowly develop the fullblown presentation of the disease at a later date. The attribution of disease to a foreign-agent would seem as old as human-kind. But only with modern Western medicine and the late nineteenth century "germ theory of disease" did this idea largely shed itself of the notion that the foreign-agent was an expression of specific social rclations. In this patient's case, however, the foreign-agent aetiology is systematically woven into the fabric of her closest relationships and metaphorically expresses them.

Finally, the patient develops the idea that God stands at a crucial point in the causal complex. She mentions that God gave her this disease in order to teach doctors how to cure it-a typical resolution of the oppositions redolent in her account of passivity and activity, receiving and giving, crime and sacrifice. She notes that in the Bible it is said to seek first and then go to the Lord, meaning, she says, go first to the medical profession and then try out religion. It is this long march that she has indeed put into practice as much as in her working through a theory of aetiology. At this stage of our discussion, she summarized a good deal of her position thus.

"You see, protein builds muscle and yet my children were lucky if they got protein once a month, and I was lucky. Now I have polymyositis, plus the arthritis, and my daughter has arthritis of the spine, and her little daughter is affected by it, has inherited it, plus her younger daughter yet. Now there seems to be a pattern there. You see I was deprived of it and my children were deprived of it and we've both come down with a chronic disease. We're not too sure that she doesn't have polymyositis. The breakdown of the muscles and the tissues due to strain and work were 
weakened by the fact that you didn't have enough protein and so on, so that when the bug comes along, you are a prime target for it!... God gives us a free will. I went very much against God's will... when I went out and got married at 15, stomped my feet and told my mother I'd go out and get pregnant if she didn't let me marry the boy. I don't believe that God gave me the disease, but he allowed ... me to get the disease. He suffered me over many mountains. And on the same hand, I was in the perfect situation for contracting the disease or for the development of the disease whether it's hereditary or catching... nobody knows yet ... Does that make sense? When I'm laying quietly thinking... the train of thought goes along and you wonder why? You know; Oh why me Lord? Why all the ups and downs? But it's not God's fault that I got sick; it's the fault of the environment I lived in! Now, with God's help which I hadn't asked for at that time, I could have overcome many of my hardships but I was too proud! And we have to be humble before God... So you see our environment has very much to do with our health and with our mental outlook on life... it has everything to do... our morals and clean living, a proper diet... all these things they all go together ... they all fit into a neat little puzzle if you sit long enough and look at them right. You have a neat little puzzle that all fits very neatly together..."

This moving passage calls for far larger commentary than I can make here. Her concern with the meaning and especially with the moral meaning of her illness stands out, reinforcing the argument that behind every reified disease theory in our society lurks an organizing realm of moral concerns. In her case, God is by no means seen as the prime or even ultimate cause of her disease. Rather, it is the moral quality of her actions, in going against her mother and so on, and the moral actions of her husband, which offended the moral code embodied in God's directives, that determined which way the potentialities inherent to her material situation or environment would develop. The elegant simplicity of Evans-Pritchard's exegesis and solution of Azande epistemology into "mystical", "scientific", and "empirical" categories, as a way of bridging their belief system with outs, becomes of dubious value. It is hard here to see a simple chain of causes stretching from ultimate to immediate, along the lines suggested by Evans-Pritchard for the Azande. Instead, we are presented with a system of internal relationships, a series of encysting and encysted contingencies permeating each other's potentials drawn into one grand pattern-or, rather, into "one neat little puzzle that all fits very neatly together".

In so far as modern medical practice ostensibly focuses exclusively on the "how" of disease, and reifies pathology in doing so, it might appear to be performing a rather helpful and healthy maneuver in expunging guilt. But as the situation so movingly reveals, nothing could be further from the truth. Through a series of exceedingly complex operations, reification serves to adhere guilt to disease. The real task of therapy calls for an archaeology of the implicit in such a way that the processes by which social relations are mapped into diseases are brought to light, de-reified, and in doing so liberate the potential for dealing with antagonistic contradictions and breaking the chains of oppression.

\section{Professionalism and reification}

In talking about her relationships with other sick people in the ward, the patient noted that "I couldn't have survived without the help of the other patients these eight weeks". She dwelt on the fact that hospitalization drew patients to one another in very personal and usually sympathetic ways. "I really do think you have a better understanding of people and their likes, dislikes, and their personalities here. Being sick gives you a tolerance for other people's faults. You really have a better bond because that person already knows your faults. You know. You don't have to put on a false face. These are things that, uh, a doctor naturally doesn't have time to sit down and think about ... They don't feel the pain. They give an order what to do but they don't feel the pain. So they really don't know what type of hazard your're going through."

She has made firm friendships with patients whom she now visits when out of hospital, but with the staff "it's different because naturally your doctor and your nurse have your medical part to think of. Where we lay here and we talk about our families and the things we like to do or the things we like to eat, you become on a more intimate basis. It's... the professional part is gone. But your doctor is still... even though he's becoming more lenient in his ways, I belicve he's still got to keep the upper hand professionally."

Following her statement that she couldn't have survived the past 8 weeks if it hadn't been for the other patients, she goes on to discuss her physical therapy. "You see I can't walk. I'm just now learning all over again from my illness. You have to learn. You have to relearn to take one step at a time ... like a child. I've been confined solely to this bed. If my tray had been left over there by the nurse ... her mind is on another medical problem that she's got to face next. But Becky who's lying in the bed next to me can get up and move over and get my stuff where I can reach it. Or ... if I can't reach my light, she'll turn her light on for me and then tell them who needs service. Now I'm able to stand if you give me the proper instructions, and, and...but you see I'm re-educating all the muscles and Becky couldn't help me there. Where see the professional, your young professional girl is trained to teach... On the other hand the professional couldn't give me the personal attention that Becky has given me. Something just as simple as pulling the curtains back so that I can see more than just a curtain and the white ceiling. I can't get up to do it myself, but Becky can. Your friendship and your mutual understandings, you know, you really get to know a person whether the're kind or really interested in you. Such as I spoke every morning very kindly to this elderly lady (in the opposite bed). I know she can hear me but she wants absolutely nothing to do with me. She's far above me. I take it she has money. Her daughter is a doctor. She wants nothing to do with me and yet I haven't hurt.her... I don't have any small children, but Becky does and I've gone through the things she is now going through so we have mutual interests. I'm the grandmother of $19 . "$ 
1 ask her why another patient couldn't help her walking. She replies. "Because she would teach you wrong, when a professional already knows and has evaluated your muscle strength. And there, uh, you know automatically that you can trust the nurse. But Becky hasn't been taught how to grab me or stabilize me... or to tell me which muscle to use to keep myself from collapsing. So, see, she can't help me professionally. So our whole friendship has to be on a ... on a I like you and you like me basis. That technician still has her mind working on far beyond mine. Mine is strictly in trying to accomplish what she has already learned and knows."

I ask; "But say the professional teaches you to walk hackwards and forwards between a couple of things several times a day. Couldn't someone like Becky who isn't bedridden help you to exercise?"

"No! Because she doesn't know the extent of your energies."

"But the professional does?"

"The professional has to figure this out before she starts the exercises."

"You yourself wouldn't know the capacity of your own energy so you could tell?"

"No! No!"

Here the loss of autonomy to which Ivan Illich refers in his book Medical Nemesis is strikingly expressed [8]. The potential within the patient as much as that which exists between patients for developing a therapeutic milieu is agonizingly cut short. The relationship with other patients becomes almost purely "expressive", while the relationship with the professionals becomes purely "instrumental". As each type of relationship is driven to its extreme in pure subjectivity and pure objectivity, so each is threatened with self-destruction as it teeters on expressiveness without substance, and instrumentation without expression or participation. The replication of our cultural epistemology into subject-hood and objecthood is here presented in its most naked form. The same epistemology is also replicated in the patient's understanding, reinforced by the professionais, of the workings of her body; namely the structure and function of musculature. As opposed to an organic conception of the inner dialectical interplay of muscles with one another and with thought and will, here muscle function is conceived of atomistically, separate from mind and will, and each muscle is objectified as something separate from the synergistic interplay of musculo-skeletal holism. And in her regarding the professional as knowing better than she as to the extent of her energies, we may well regard the alienation of her own senses as complete, handed over to the professional who has become the guardian or banker of her mind.

This splitting of subjectivity from objectivity as represented by patient-good and professionalism, respectively, resulting in the capturing of her subjectivity by the professional, is as much a result of the patients' inability to develop the mutual aid potential still present in the patient sub-culture as it is due to the relationship between professional and patient. The former derives from the latter, and both contrast strikingly with the social relations and culture described by Joshua Horn for the Chinese hospitals in which he worked from 1954 to 1969.
The patients often select representatives to convey their opinions and suggestions to teams of doctors, nurses and orderlies who have day-to-day responsibility in relation to specific groups of patients. These teams meet daily to plan the day's work. Ambulant patients play an active part in ward affairs. They take their meals in the ward diningroom and many of them help patients who are confined to bed, reading newspapers to them. keeping them company and becoming familiar with their medical and social problems. I conduct a ward round in a different ward each day and as I do so. I usually collect a retinue of patients who go with me, look and listen and often volunteer information [9].

The alienation of the patient's self-understanding and capacity is all the more striking when we learn that she has extensive practical experience with physical therapy and that out of the hospital context and away from the aura of professionals, she docs in fact regard herself as skilled and powerful in this regard. Speaking about her sprained knee suffered some years back she says. "And then I had to learn to walk again. I'm always learning to walk! I really ought to be welltrained. I could be a therapist... I trained my daughter after she had polio. And they refused to take her at the polio center. I taught her to walk. Her left side was paralyzed (the same side that the patient always refers to as her weak and occasionally almost paralyzed side)... I learnt from a friend. I used to have to get up and I'd sit on top of her and stretch her hamstrings and stretch her arm muscles and things and it was 3 months before I got any response at all. And then one night when I was stretching her hamstrings she screamed because she said that it hurt too much. Well I sat down and had a good cry. Mother couldn't even continue therapy that night. And from then on, the more it hurt, the more therapy I gave her. And the year from the day that they told me she'd never walk again, I walked back in to the doctor and I showed her what one person could do with God's help. You have to be gentle. And this comes from love, compassion, and the desire to help another human being. And you'd be surprised how really strong my hands are I never lose the strength of my hands. I don't know why. But through all of this I have never completely lost my... my hands."

So, we are faced with a contradiction. And this contradiction is just as much present in the hospital situation and in the professional-patient relationship so that the loss of autonomy and the cultural lobotomization is never complete. For a few days later the patient refused what was considered an important part of her treatment, just as during an earlier stay in hospital she created a wild scene by throwing her coffee on the floor when the staff refused to give her more medication for pain.

On this earlier occasion she insisted that her pain was increasing. The staff regarded this as "secondary gain". The nurses" plan was to "give support and reassurance; allow the patient to express her feelings. Monitor emotion regarding status and shift". It is, of course, this mode of perception-"monitor emotion..."--which so tellingly contrasts with the type of observation that passes between patients, and which should be referred back to my earlier citation from Foucault, the perception which 
does not allow of reciprocity: only the nearness of an observation that watches, that spies, that comes closer in order to see better, but moves ever further away, since it accepts and acknowledges only the value of the Stranger.

Following the innovation and supposedly more humane "problem-oriented approach", which is now also taught to medical students, the nurses' progress notes are written up in the form of the different problems the patient has. Each problem is then analysed into four parts in accord with the S.O.A.P. formula: Subjective (the patient's perception), Objective (the nurse's observation), Analysis (interpretation of data), and Plan. Soap-the guarantee of cleanliness and the barrier to pollution! Subjectivity, objectivity, analysis, and plan! What better guarantee and symbolic expression could be dreamt of to portray, as if by farce, the reification of living processes and the alienation of subject from object? And, as one might suspect, this formulation is congruent with the need for computerizing records and more rationally preparing safeguards against malpractice suits. The Plan? "Give support and reassurance. Relate feelings of trust." How much does this packaging of "care", "trust", and "feelings", this intstrumentation of what we used to think of a spontaneous human transitiveness and mutuality, cost, according to Blue Cross?

A few days later, the patient complained of more pain, and of her inability to urinate (although according to the nursing staff she could urinate). The night following she became angry and threw her coffee at a nurse who then called a doctor. He reported; "Patient had a significant episode of acting out. Accused nursing personnel and myself of lying and disrespect. Extremely anxious and agitated. Crying. Had thrown a cup of coffee at the R.N. (Registered Nurse). Patient refused to acknowledge any other precipitating event or underlying emotion. Husband arrived and calmed patient down. Psychiatric recommendation with $\mathrm{Dr} Y$ and began initiating dose of Haloperidol. Will also add $75 \mathrm{mg} /$ day amitriptiline for apparent on-going depressive state with anxiety." (Haloperidol is described by Goodman and Gillman [10] as a drug which calms and induces sleep in excited patients. Because it produces a high incidence of extrapyramidal reactions it should be initiated with caution.) This is the first time that the doctor's notes mention that the patient is distressed, although the nurses' notes chart her increasing dissatisfaction going back over several days. The nurse's report of the same incident leaves out, for the first time, the $S$ (subjective category) and goes straight to Objectivity: "Patient was so upset when she was told that somebody said that she can get out of bed and use the bedside commode. She said that nurse is... and for her anger threw her cup of coffee on the floor. Crying and wants her husband to be called because she's very upset. Saying dirty words." Analysis: "Patient is very upset". Plan: Dr X notified and patient was told to calm down since she's not the only patient on the floor, that others are very sick and upset from her noise. Patient claims that she is not sick. Patient quiets down when her husband came and friendly to the nurses." The next day the doctor's notes say that the patient is quite angry and that her anger takes the form of sobbing and threatening to leave hospital and warn friends about care here. The day after that, the nurses report that the chaplain talked to the patient for half an hour so she'll be able to release all her tensions, anxiety, and conflict. The chaplain said that she's angry of something. The Plan notes that the chaplain will come every day and that she's a bit nicer to the staff and courteous when she needs something. The doctor's notes describe the patient as "stable" and thereafter never mention her scene. The nurse's report says that she is still complaining of pain, Subjective category, and requesting pain medication, Objective category. As for her "anxiety problem" the Objective entry says "she is talking about how people don't believe she can do nothing for herself." And the next day she went home.

It is surely of some importance that the patient was examined (sic) by a psychiatrist the morning of the same day when she later threw her coffee (on the floor, according to the nurses; at a nurse, according to the doctor). The nurses' report noted that she was crying and trembling following the visit of the psychiatrist, whose own report says that the "evidence is strongly suggestive of an organic brain syndrome". She said it was January when it was December. The psychiatrist had just wakened her. She "demonstrated some looseness of associations", "at times was difficult to follow as she jumped from topic to topic", and on serial subtractions from 50 she made three errors. Having stated that the evidence was strongly suggestive of an organic brain syndrome (i.e. a physical disease of the brain) the psychiatrist in his Recommendations wrote: "Regarding the patient's organic brain syndrome..." In other words, what was initially put forward as a suggestion (and what a suggestion!) now becomes a real thing. The denial of authorship could not be more patent.

The significance of this episode is that apart from illustrating yet another horror story of hospitalization it reveals how the clinical situation becomes a combat zone of disputes over power and over definitions of illness and degrees of incapacity. The critical issue centers on the evaluation of incapacity and of feelings, such as pain, and following that on the treatment necessary. Here is where the professionals deprive the patients of their sense of certainty and security concerning their own self-judgement.

By necessity, self-awareness and self-judgement require other persons' presence and reflection. In the clinical situation, this dialectic of self and other must always favor the defining power of the other written into the aura of the healer who must therefore treat this power with great sensitivity lest it slip away into a totally one-sided assertion of reality, remaining a relationship in name only. The healer attempts to modulate and mold the patient's self-awareness without dominating it to the point of destruction, for if that happens then the healer loses an ally in the struggle with dis-ease. Yet, as illustrated in this case study, a quite vicious procedure precludes this alliance and the patient is converted into an enemy. It is not, as Illich maintains, for example, that patients lose their autonomy. Far from it. Instead, what happens is that the modern clinical situation engenders a contradictory situation in which the patient swings like a pendulum between alienated passivity and alienated selfassertion. 
Paradoxically, this follows from an ever-increasing self-consciousness on the part of health professionals to be more humane and to self-consciously allow the patient's definition of the problem a privileged place in the medical dialogue, only to co-opt that definition in a practice which becomes more rationalized as it becomes less humanized. This rationalization amounts to an attempt to wrest control from the patient and define their status for them by first compartmentalizing the person into the status of patienthood, then into the status of thing-hood as opposed to that of a mutually interacting partner in an exchange, and then into the categories of Objective and Subjective, working through these reifications by an Analysis and a Plan. The analogy with the rationality of commodity production is complete. As with automobiles on the assembly-line, so with patients and with health itself, the difference, the pathos, and the occasional problem bearing mute testimony to the fact that unlike automobiles, patients do think and feel, and that sickness is as much an interactive human relationship as a thing-in-itself.

$\mathrm{My}$ intention here is not only to direct attention to the callousness that results. In addition, we have to deal with the complicated mystification present in healing in any culture, but which in our own modern clinical setting perniciously cannibalizes the potential source of strength for curing which reposes in the inter-subjectivity of patient and healer. In the name of the noble cause of healing, the professionals have been able to appropriate this mutuality and in a very real sense exploit a social relationship in such a way that its power to heal is converted into the power to control. The problems that ensue, at least as illustrated in this case study, lie in the very nature of the clinical setting and therefore are especially opaque to the therapists. As the Chaplain so forlornly noted, "She's angry of something," and this anger stems from the contradictions which assail the patient. On the one hand she sees the capacity for "mere" patients to form a therapeutic community. But on the other hand, she denies the flowering of this potential because of her being forced to allow the professionals to appropriate her discretionary powers, while at another instant she rebels against this appropriation. The circuit of reification and re-subjectification is inherently unstable. Hcalth professionalization of this all too common type does not guarantee the smooth control that the staff demand, let alone what patients need. All of which will assuredly be met by yet further rationalization and more professionalization.

On her later admission to hospital and shortly after first talking to me about patients supporting one another, only to claim that it required a professional therapist to help her walk, the patient suddenly refused the ministrations of the Occupational Therapists. She complainted that all her day was taken up with therapy, that the Occupational Therapist took an hour a day, and that she had time neither to use the bedpan, to comb her hair, nor to listen to her religious music. "When I'm sick," she declared, "I can't work eight hours a day! And yet the whole theory of my disease and getting better is rest. And so I broke down this morning and I told the Occupational Therapist I had to cut her hour out. I've got to make an hour sometime during the day when I can just relax and not be getting in and out of a chair which hurts me severely. There's no time for anything of a personal nature... so the stress and the emotional conflict is there. And there's never any time to solve it by myself. And there was no place ... because there are only eight hours. I can't put twelve hours into eight!"

Again we see that the passive alienation embodied in her relation with the professionals, which at first sight appears to be a fait accompli. registers an abrupt rupture, a "scene", which ripples panic amongst the staff.

The Occupational Therapists, the Physical Therapists and the Social Workers were all deeply upset by this gesture which they saw as a denial of their efficacy and of their jobs. When I asked them why they couldn't leave her alone for a week, their leader replied, "It's my Blue Cross, Blue Shield payments as much as hers!" So, they drew up a contract with the patient, nowadays a typical procedure in the hospital as it is in many U.S. schools.

\section{Contracting}

The staff and the patient both sign a written contract stating, for example, "What you do have choices about." "What you do not have choices about," "Objectives," "What we will do," "What you will do." In this patient's case the contract stated as "objective", walk 30 feet three times a day. "What we will do," protect two 45 min rest periods. "What you will do," try and walk. The underlying motive, as described by some theorists of medical contracting, is that the staff will reward the patient for complying with their desires (positive reinforcement), rather than falling into what is seen as the trap of the old style of doing things which, supposedly, was to reinforce noncompliance by paying more attention to such behavior than to compliance. It is, in short, Behaviorism consciously deployed on the lines of market contracts in order to achieve social control. It is the medication of business applied to the business of medicine. Rewards cited in the academic and professional journals dealing with this subject are lottery tickets, money, books, magazines, assistance in filling out insurance forms, information, and time with the "health care provider" [11]. It has been found that patients often choose more time with the "health provider" and help in untangling bureaucratic snarls so as to obtain insurance benefits and medical referrals.

The very concept of the "health care provider", so disarmingly. straightforward, functional, and matterof-fact, is precisely the type of ideological labelling that drives patients into so-called non-compliance. The "health care provider", in antediluvian times known as the nurse, doctor, etc., does not provide health! Health is part of the human condition, as is disease, and the incidence and manifestations of both are heavily determined by the specificities of social organization. Health care depends for its outcome on a two-way relationship between the sick and the healer. In so far as health care is provided, both patient and healer are providing it, and, indeed, the concern with so-called non-compliance is testimony to that, in a back-handed way. By pre-establishing the professional as the "health care provider", the inherited social legacy that constitutes medical wisdom and 
power is a priori declared to be the legitimate monopoly of those who can convince the rest of us that this wisdom comes from society and nature in a pre-packaged commodity form which they and only they can dispense. And in choosing as rewards for non-compliant patients help in overcoming the snarls which the "health care providers" provided, is to heap absurdity on deception. But the real pathos in this is neither the absurdity nor the deception. It is that it appears, in our day and age, to be so perfectly straight-forward and reasonable. This is the mark of ideology; its naturalness. And if its nature is to be found in the realm and language of marketing, so that medical culture and healing too succumb to the idiom of business, then we must not be all that surprised. For ours is the culture of business which puts business as the goal of culture.

In the same way that freedom and a specific type of individualism came long ago to be asserted with the rise of the free market economy, so the introduction of contracting in healing today is seen by its proponents to be a bold blow for the assertion of human rights, shattering the mystification of the feudal past when patients complied with doctors' commands out of blind trust. The proponents of contracting in clinical settings also tell us that the doctrine on which it is based, Behaviorism and the "laws" of reinforcement and extinction, have led to "the treatment of maladaptive human behaviors, including psychoses, retardation, alcoholism, low work productivity, and criminality" [12].

Maladaptation is of course not a thing, but a purely normative concept travelling under the disguise of scientific jargon. More often than not it serves in contexts such as these to smuggle in a particular intention or value by making it appear to be a fact like a fact of nature. The assimilation of low work productivity, criminality, and psychosis to one another as parts of the same fact, maladaptation, and now to patients who disobey doctors' "orders", serves to remind us just how colossal a distortion is involved by reifying social relations so that pointed political vulues smuggled under the guise of technical constructs remain immune to criticism. stamped with the authority of the hard and impenetrable scientific fact. Once again, the nature of truth is seen to lie in the truth of nature, and not in some critical way as dependent upon the social organization of facts and nature.

In the case of the patient described in this case study we might note the following. She had every good reason for not complying with the staff.s orders. This reason was not appreciated by the staff. It was seen as a threat to their power and to the coffers of Blue Cross. It was not the case, as the aforementioned authorities on contracting say, that because she was non-compliant she was getting more attention from the staff. It was totally the opposite. When she was complying she was getting too much attention, and all she wanted was free time. The immediate cause of her frustration was intimately related to the bureaucratic pressure of her daily routine. The contracting strategy chosen by the staff was thus ingeniously selected to meet this by further bureaucratizing an agreement, the contract, so as to formally deformalize her time into therapy time and "free time," time which any freedom lover would have naively thought was hers in the first place, anyway, and not something to be owned and dispensed by the staff. The idea that she was free to choose and contract, and the idea that contracting per se is both sign and cause of freedom, is as pernicious an illusion that the free time the staff were granting her was not rightfully hers in the first place.

The argument in favor of contracting, that it clears away the mystifications in the murky set of understandings existing between doctor and patient, that it increases the power, understanding, and autonomy of the patient, is a fraud. Moreover, it is a fraud which highlights the false consciousness as to freedom and individualism upon which our society rests. Can autonomy and freedom be really said to be increased when it is the staff which has the power to set the options and the terms of the contract? If anything, autonomy and freedom are decreased because the illusion of freedom serves to obscure its absence. Furthermore, the type of freedom at stake in the contracting amounts to a convenient justification for denying responsibility and interpersonal obligations, just as in the name of contract and free enterprise the working class at the birth of modern capitalism was told that it was as free and as equal as the capitalists with whom they had to freely contract for the sale of their laborpower. There is little difference between that situation, the capitalist labor market, and the one which concerns us wherein the clinical setting becomes a health market and one contracts as a supposedly free agent with the "health care providers" so as to grant the latter the right to appropriate the use-value power embodied in the healing process.

Far from increasing patient autonomy (as its proponents argue), the design of contracting is unabashedly manipulative.

Requests for $15 \mathrm{~min}$ of uninterrupted conversation with a team member, games of checkers, cards and chess. Bible reading, discussion of current events and visits from various team members are examples of rewards chosen by patients. Such examples as these imply that patients place considerable value on our interactions with them. It also indicates that because patients value our relationships with them, we are in a powerful position for influencing the choice of behavior the patient ultimately makes; e.g. compliance versus non-compliance [13].

Just as we were wont to believe that medical care differed from business, as in Talcott Parsons' analysis whereby the "collectivity orientation" of the medical profession was opposed to the business ethic of selfinterest, only to become increasingly disillusioned, so now we find that even friendship is something to be bargained for and contracted by $15 \mathrm{~min}$ slots. After all, if health becomes a commodity to be bought and sold, is it any wonder that friendship should likewise become a commodity? And if social relations and friendship become things, like this, it is equally unsurprising that the subject becomes object to him or herself so that

the patients find it very rewarding to improve their own baseline. This perhaps is the most meaningful reward of all Improving one's baseline indicates to the patient that he is essentially competing against himself. $\mathrm{He}$ views himself as 
the one controlling his own behavior. This eliminates the need for increased interaction when the behavior is unacceptable. In other words, the patient graphically knows his behavior is unacceptable and we as professionals are free to "ignore" the unacceptable behavior [14].

\section{ANTHROPOLOGY: THE NATIVES POINT OF VIEW}

If contracting represents the intrusion of one dimension of the social sciences, Behaviorism, into medical practice so as to improve and humanize medical care, then Anthropology too has something to add; namely a concern with the native's point of view. The idea here, as put forward by Kleinman et al. [16] in a recent article in the presitigious Annals of Internal Medicine, is that disease and illness represent two different realities and that illness is shaped by culture. Disease represents organ dysfunction which can be modified by the pathologist and measured in the laboratory, while illness is what that dysfunction means to the person suffering it. Cirrhosis of the liver, for instance, can be represented in "disease" terms; by the micropathologist in terms of the architectural distortion of tissue and cellular morphology, by the biochemist in terms of changes in enzyme leveis, and so on. But to the person afflicted with the "disease", it means something else and this something else is the "illness" dimension; the cultural significance of the term "cirrhosis," the meanings read into the discomforts, symptoms, signs, and treatment of the "disease", and so on. This is the native's point of view and it will of necessity differ from the doctor's "disease" viewpoint. Stemming from their reading of Anthropology and from their own experience with folk medicine in Third World cultures, Kleinman et al. hold this difference between "disease" and "illness" to be of great importance. They advocate an addition to the training of medical personnel so that they too will become aware of this difference and act on it. This they call "clinical social science" and its focus shall be with the "cultural construction of clinical reality". Learning and applying this shall improve doctor-patient relationships and the efficacy of therapy, overcoming the communication gap between the "doctor's model of disease" and the "patient's model of illness". As with contracting, non-compliance and the management of human beings is of prime concern.

Training modern health professionals to treat both disease and illness routinely and to uncover discrepant views of clinical reality will result in measurable improvement in management and compliance, patient satisfaction, and treatment outcomes [16].

Elucidation of the patient's model of illness will aid the clinician in dealing with conflict between their respective beliefs and values. The clinician's task is to educate the patient if the latter's model interferes with appropriate care. Education by the clinician is seen as a process of "negotiating" the different cognitive and value orientations, and such negotiation "may well be the single most important step in engaging the patient's trust" (Kleinman et al. [17]). Like so much of the humanistic reform-mongering propounded in recent times, in which a concern with the natives' point of view comes to the fore, there lurks the danger that the experts will avail themselves of that knowledge only to make the science of human management all the more powerful and coercive. For indeed there will be irreconcilable conflicts of interest and these will be "negotiated" by those who hold the upper hand, albeit in terms of a language and a practice which denies such manipulation and the existence of unequal control. The old language and practice which left important assumptions unsaid and relied on an implicit set of understandings conveyed in a relationship of trust is to be transformed. The relationship is now seen in terms of a "provider" and a "client", both "allies" in a situation of mutual concern. Kleinman et al. demonstrate this democratic universe in which far from cleaning up the old-fashioned mystifications as embodied in trust relationships, new mystifications are put in their place which are equally if not more disturbing. With their scheme the clinician

mediates between different cognitive and value orientations. He actively negotiates with the patient as a therapeutic ally .... For example, if the patient accepts the use of antibiotics but believes that the burning of incense or the wearing of an amulet or a consultation with a fortune-teller is also needed, the physician must understand this belief but need not attempt to change it. If, however. the patient regards penicillin as a "hot" remedy inappropriate for a "hot" disease.and is therefore unwilling to take it, one can negotiate ways to "neutralize" penicillin or one must attempt to persuade the patient of the incorrectness of his belief, a most difficult task [17].

It is a strange "alliance" in which one party avails itself of the other's private understandings in order to manipulate them all the more successfully. What possibility is there in this sort of alliance for the patient to explore the doctor's private model of both disease and illness, and negotiate that? Restricted by the necessity to perpetuate professionalism and the ironclad distinction betwcen clinician and patient, while at the same time exhorting the need and advantage of taking cultural awareness into account, these authors fail to see that it is not the "cultural construction of clinical reality" that needs dragging into the light of day, but instead it is the clinical construction of reality that is at issue.

\section{THE CULTURAL CONSTRUCTION OF CLINICAL REALITY, OR THE CLINICAL CONSTRUCTION OF CULTURE?}

This is where sensitive anthropological understanding truly sheds light. The doctors and the "health care providers" are no less immune to the social construction of reality than the patients they minister, and the reality of concern is as much defined by power and control as by colorful symbols of culture, incense, amulets, fortune-telling, hot-and-cold, and so forth.

What is signiticant is that at this stage of medicine and the crises afflicting it, such a project should emerge. What is happening is that for the first time in the modern clinical situation, an attempt is underway to make explicit what was previously implicit, but that this archaeology of the implicit cannot escape the demands for professional control. The patient's socalled model of illness differs most significantly from the clinician's not in terms of exotic symbolization 
but in terms of the anxiety to locate the social and moral meaning of the disease. The clinician cannot allow this anxiety to gain either legitimacy or to include ever-widening spheres of social relationships, including that of the hospital and the clinician, for more often than not once this process of thought is given its head it may well condemn as much as accept the contemporary constitution of social relationships and society itself.

Attempts such as those advocated by Kleinman et al. to make explicit what was previously implicit, merely seize on the implicit with the instruments of modern social science so to all the better control it. Yet in doing so they unwittingly reveal all the more clearly the bare bones of what really goes on in an apparently technical clinical encounter by way of manipulation and mediation of contradictions in society.

The immediate impulse for this archaeology of the implicit, this dragging into consciousness what was previously left unsaid or unconscious in medical practice, comes at a time when the issue of the so-called non-compliant patient (like the illiterate schoolchild) is alarming the medical establishment, now concerned as never before with the rationalization of the health assembly-line and with rising costs. In this regard, it is a scandal and also self-defeating to appeal to Anthropology for evidence as to the power of concepts like the "patient's model" and the difference between the "how" and the "why" of "disease" and "illness". For the medical anthropology of so-called "primitive" societies also teaches us that medicine is preeminently an instrument of social control. It teaches us that the "why" or "illness" dimension of sickness bears precisely on what makes life meaningful and worthwhile. compelling one to examine the social and moral causes of sickness, and that those causes lie in communal and reciprocal inter-human considerations which are antithetical to the bases of modern social organization patterned on the necessities of capitalist and bureaucratic prerogatives. As Victor Turner concludes in his discussion of the Ndembu doctor in rural Zambia:

It seems that the Ndembu "doctor" sees his task less as curing an individual patient than as remedying the ills of a corporate group. The sickness of the patient is mainly a sign that "something is rotten" in the corporate body. The patient will not get better until all the tensions and aggressions in the groups interrelations have been brought to light and exposed to ritual treatment ... The doctor's task is to tap the various streams of affect associated with these conflicts and with the social and interpersonal disputes in which they are manifested, and to channel them in a socially positive direction. The raw energies of conflict are thus domesticated in the service of the traditional social order [18].

And Lévi-Strauss reminds us in his essay, "The Sorcerer and His Magic", that the rites of healing readapts society to predefined problems through the medium of the patient; that this process rejuvenates and even elaborates the society's essential axioms [19]. Charged with the emotional load of suffering and of abnormality, sickness sets forth a challenge to the complacent and everyday acceptance of conventional structures of meaning. The doctor and the patient come together in the clinic. No longer can the community watch them and share in this work. Nevertheless, whether the patient wants to accept penicillin or not, whether the rest of us are physically present in the clinic or not, the doctor and the patient are curing the threat posed to convention and to society, tranquilizing the disturbance that sickness unleashes against normal thought which is not a static system but a system waxing, consolidating and dissolving on the reefs of its contradictions. It is not the cultural construction of clinical reality that is here at issue, but the clinical construction and reconstruction of a commoditized reality that is at stake. Until that is recognized, and acted upon, humanistic medicine is a contradiction of terms [20].

\section{REFERENCES}

1. Lukács $G$. Reification and the class consciousness of the proletariat. In History and Class Consciousness, pp. 83-222. Merlin Press, London, 1971.

2. Evans-P̈ritchard E. E. Witchcraft, Oracles and Magic among the Azande. Clarendon Press, Oxford, 1937.

3. Sartre J. P. Being and Nothingness. Abridged edition. pp. 279-80. Citadel Press, Seacus, New Jersey, 1956.

4. Radin P. Primitive Man as a Philosopher, p. 274. Dover, New York 1957.

5. Sontag S. Illness as Metaphor. Farrer, Strauss \& Giroux, New York, 1978.

6. Linder R. Diagnosis: description or prescription? Percept. Mot. Skills 20, 1081, 1965; cited in Blaxter M. Diagnosis as Category and Process: the Case of Alcoholism. Soc. Sci. Med. 12, 12, 1978.

7. Foucault M. Madness and Civilization. p. 202. Mentor Books. New York. 1967

8. Illich I. Medical Nemesis. Caldar \& Boyars, London. 1975.

9. Horn J. Away with All Pests, p. 53. Monthly Review Press, New York, 1969.

10. Goodman L. and Gilman A. (Eds) The Pharmacological Basis of Therapeutics, 5th edn, pp. 166-67. Macmillan, New York, 1975.

11. Boehm Steckel S. and Swain M. Contracting with patients to improve compliance. J. Am. Hosp. Ass. 51, $82,1977$.

12. Boehm Steckel S. and Swain M., op. cit., p. 81.

13. Boehm Steckel $S$. The use of positive reinforcement in order to increase patient compliance. J. Am. Ass. Nephrol. nurs. Technic. 1, 40, 1974.

14. Boehm Steckel S. ibid.

15. Kleinman A., Eisenberg L. and Good B. Culture, illness and care: clinical lessons from anthropologic and cross-cultural research. Ann. intern. Med. 88, 1978.

16. Kleinman A. et al., op. cit. p. 256.

17. Kleinman A. et al., op. cit. p. 257

18. Turner V. A Ndembu doctor in practice. In The Forest of Symbols, p. 392. Cornell Univ. Press, Ithaca, 1967.

19. Lévi-Strauss C. The sorcerer and his magic. In Structurul Anthropology, pp. 161-80. Anchor Books, New York, 1967.

20. I wish to thank Drs Tom O'Brien and Steve Vincent for helping me begin this project, and the members of the 1977 Marxist Anthropology seminar at the University of Michigan. Ann Arbor, for their comments on an early draft of this paper. 